\title{
Evolving landscape and novel treatments in metastatic castrate-resistant prostate cancer
}

\author{
Paul J Toren and Martin E Gleave
}

Treatment options for castrate-resistant prostate cancer (CRPC) have advanced in recent years and significantly improved the outlook for patients with this aggressive and lethal disease. Further understanding of the biology of CRPC has led to several new targeted therapies and continues to emphasize the importance of androgen receptor (AR) directed therapy. The treatment landscape is rapidly changing and further biologically rationale, biomarker-based ongoing clinical trials are needed. We review the recent results of major clinical trials in CRPC. New and investigational agents now in clinical evaluation are reviewed including inhibitors of angiogenesis, microtubules, chaperones, AR and intracellular kinases, as well as immunotherapy, radiopharmaceuticals and bone-targeted agents. The recent improvement in prognosis for CRPC brings continued optimism for further improvements. Thoughtful planning of clinical trials and further understanding of the mechanisms of resistance to therapies will allow for continued progress in patient care. Asian Journal of Andrology (2013) 15, 342-349; doi:10.1038/aja.2013.38; published online 15 April 2013

Keywords: prostate cancer; treatment resistance; androgen receptor antagonists; molecular targets

\section{INTRODUCTION}

Treatment for advanced prostate cancer has evolved since Huggins and Hodges found a significant response with castration and estrogens in metastatic prostate cancer over 70 years ago. ${ }^{1}$ With an expanding knowledge of the molecular targets and mechanisms of resistance, the prognosis for patients with metastatic castrate-resistant prostate cancer (CRPC) has improved significantly in the last decade. Nonetheless, most tumours inevitably develop resistance and progress. This review provides an overview of the evolution of the current treatment landscape for metastatic CRPC and the novel therapeutics which are currently in clinical evaluation.

\section{EPIDEMIOLOGY OF CRPC}

CRPC is a heterogeneous and progressive stage of prostate cancer, including both symptomatic and asymptomatic men with or without clinical metastases. CRPC is defined according to the Prostate Cancer Clinical Trials Working Group as progression of prostate cancer despite castrate levels $\left(<1.7 \mathrm{ng} \mathrm{ml}^{-1}\right)$ of testosterone. Progression may be biochemical (three consecutive prostatespecific antigen (PSA) rises $>2 \mathrm{ng} \mathrm{ml}^{-1}$ above nadir, minimum 1 week apart) or radiological or symptomatic. ${ }^{2}$ Approximately $10 \%-20 \%$ of men castrated for prostate cancer treatment develop CRPC within 5 years of follow-up. ${ }^{3,4}$

The median age of men with CRPC is in the seventies. ${ }^{3,5}$ Up to $85 \%$ of patients at diagnosis with CRPC will have metastases. ${ }^{4}$ By comparison, approximately $4 \%$ of all newly diagnosed prostate cancer patients present with metastatic disease. ${ }^{6}$ The classification of metastatic versus non-metastatic CRPC is important to distinguish. Prognosis and natural history is variable, with a less aggressive course in non-metastatic CRPC. One study estimated approximately $30 \%$ of men with a rising PSA and no bone metastases developed bone metastases at 2 years. ${ }^{5}$ Notably, absolute PSA levels and PSA kinetics continue to maintain usefulness in CRPC as biomarkers predictive of prognosis. 5,7

\section{HISTORICAL TREATMENT LANDSCAPE}

Historically, treatment for metastatic CRPC was largely palliative. Mitoxantrone showed a benefit for palliation, ${ }^{8}$ but it was not until the SWOG 9916 and TAX 327 studies that an improvement in overall survival (OS) was noted with chemotherapy. ${ }^{9,10}$ Treatment has largely consisted of continued medical or surgical androgen deprivation therapy. Anti-androgens, particularly bicalutamide, have also been used in combination with androgen deprivation therapy, but with only a modest survival benefit. ${ }^{11}$ Bone targeted therapy with zoledronic acid also entered clinical practice at a similar time as the early chemotherapies. ${ }^{12}$ Radiopharmaceuticals were known to have a palliative benefit, but were sparsely used, in part due to haematological toxicity. External beam radiotherapy to symptomatic sites was and continues to be an effective and widely used treatment for bone metastases, though its incident use is not well reported. ${ }^{4}$

Historically, the median survival of men with metastatic CRPC has been reported as low as 1 year, ${ }^{8}$ though with improvements in care as well as earlier labelling of the CRPC state, the median survival now is approaching 2.5 years. Moreover, both survival and quality of life continue to improve with the introduction of new therapies. However, not all the improvements in survival are related to new therapies available. It is noteworthy that the median OS in the placebo arm of CRPC trials appears to increase over time (Table 1). For 
Table 1 Improving survival in metastatic castrate-resistant prostate cancer: results of selected phase III trials

\begin{tabular}{|c|c|c|c|c|c|c|}
\hline Trial (reference) & Year & Disease state & Intervention arm & Control arm & $\begin{array}{c}\text { HR (95\% confidence } \\
\text { interval) }\end{array}$ & $\begin{array}{c}\text { Median OS } \\
\text { (month) }\end{array}$ \\
\hline PR-6 ${ }^{7}$ & 2003 & First-line, symptomatic & Clodronate + MP & MP & $0.95(0.71-1.28)$ & 10.8 vs. 11.5 \\
\hline $\operatorname{TAX} 327^{8}$ & 2004 & First-line & DP every 3 weeks & MP & $0.76(0.62-0.94)$ & 18.9 vs. 16.5 \\
\hline IMPACT $^{74}$ & 2010 & First-line, asymptomatic & Sipuleucel-T & Placebo & $0.78(0.61-0.98)$ & 25.8 vs. 21.7 \\
\hline TROPIC 33 & 2010 & Second-line & Cabazitaxel+prednisone & MP & $0.70(0.59-0.83)$ & 15.1 vs. 12.7 \\
\hline COU-AA-301 46 & 2011 & Second-line & Abiraterone + prednisone & Placebo+prednisone & $0.65(0.54-0.77)$ & 14.8 vs. 10.9 \\
\hline ALSYMPCA $^{90}$ & 2011 & Second-line or palliative & Alpharadin & Placebo & $0.70(0.55-0.88)$ & 14.9 vs. 11.3 \\
\hline AFFIRM $^{39}$ & 2012 & Second-line & Enzalutamide & Placebo & $0.63(0.53-0.75)$ & 18.4 vs. 13.6 \\
\hline ENTHUSE $^{69}$ & 2012 & First-line, asymptomatic & Zibotentan & Placebo & $0.87(0.69-1.10)$ & 24.5 vs. 22.5 \\
\hline CALGB $90401^{10}$ & 2012 & First-line & $\mathrm{DP}+$ bevacizumab & DP & $0.91(0.7-1.05)$ & 22.5 vs. 21.5 \\
\hline COU-AA-302 47 & 2012 & First-line, asymptomatic & Abiraterone+prednisone & Placebo+prednisone & $0.75(0.63-0.91)$ & NR vs. 27.2 \\
\hline
\end{tabular}

Abbreviations: DP, docetaxel+ prednisone; HR, hazard ratio; MP, mitoxantrone+prednisone; NR, not reached; OS, overall survival.

example, the survival in the docetaxel/prednisone control arm of the CALGB 90401 was 21.5 months, 2.6 months longer than the original TAX327 study. ${ }^{9,13}$ Palliative care and supportive care have also improved. While not extensively studied, there are suggestions that palliative external beam radiotherapy may provide some survival benefit. ${ }^{14}$ More recently, for men treated only with prednisone, the median survival was 27.2 months in the COU-302 trial. ${ }^{15}$

\section{ROLE OF THE ANDROGEN RECEPTOR (AR) IN CRPC}

The AR was first characterized in the $1960 \mathrm{~s}^{16}$ and continues to be an enduring target in prostate cancer. Upon binding to dihydrotestosterone (DHT) in the cytoplasm, it subsequently is translocated into the nucleus. There, the AR binds to the DNA response elements and initiates translation of mRNA, which eventually drives cell growth and proliferation. It was previously thought that once prostate cancer progressed, despite androgen deprivation, the AR was no longer driving tumour growth. Thus, there was stronger rationale to target rapidly dividing cells with non-AR targeted therapy; the success of docetaxel targeting rapidly dividing cells strengthened this viewpoint. This perspective on CRPC has changed through a better understanding of the biology of CRPC, as well as the recent success of abiraterone and enzalutamide for treating CRPC. Thus, the terms 'hormone-refractory', or 'androgen-independent' are inappropriate descriptors and no longer in use. Neuroendocrine prostate cancer represents a small subset of cancers which undergo radical genomic changes and are no longer AR-driven. It is possible the increased use of more potent AR-directed therapy may result in a greater prevalence of neuroendocrine prostate cancer.

Several AR-mediated mechanisms of resistance have been proposed and include activation of a promiscuously mutated AR, AR gene amplification, intratumoural production of androgens, recruitment of transcription factors and gene fusions or re-arrangements. ${ }^{17-21}$ Deep sequencing has identified genomic alterations of the AR in CRPC in approximately $50 \%$ of cases. ${ }^{22}$ More broadly, the AR pathway is estimated to be altered in $\sim 50 \%$ of primary prostate cancers and $100 \%$ of metastases. ${ }^{21}$ The role of the AR pathway in resistance to newer AR-targeted therapies continues to be explored. Upregulation of certain enzymes in the steroidogenesis pathway and constitutively active AR splice variants without the ligand-binding domain are two mechanisms of interest. ${ }^{23,24}$

Several other pathways are also known to be aberrant in CRPC and may be targets for future combination strategies with AR-directed therapy. The mTOR/PI3K/Akt pathway appears to be involved in crosstalk with the AR pathway. ${ }^{25}$ Other kinase signalling pathways such as IRS-1, c-met, MAPK and SEMA3C may also be relevant targets. ${ }^{26-28}$ Cotargeting the stress response, activated by AR inhibition and mediated through stress-activated cytoprotective chaperones like clusterin or Hsp27, may create conditional lethality and improve outcomes. ${ }^{29,30}$ Transcription factors such as Stat 3 and cytokines such as NF- $\kappa \mathrm{B}$ and IL-6 are also implicated in CRPC progression. ${ }^{31}$ Understanding the temporal and clinical relevance of these aberrant pathways with the AR may allow for rationale cotargeting approaches.

\section{CONCEPTUALIZING THE TREATMENT PARADIGM}

With docetaxel as the first and only agent to improve survival in CRPC until recent years, the treatment space in CRPC has often been defined as pre- and post-chemo. However, with many new therapies emerging into practice, this paradigm is now changing. Similar to other cancers, the lexicon of treatment options has evolved towards first-, secondand third-line options as the disease progresses (Figure 1). AR pathway inhibition, with greater improvements in median survival and death rates, as well as less side effects, compared to docetaxel, now represents first-line therapy. However, the landscape is more complex than simply whether or not patients have evidence of cancer progression (e.g., rising PSA, pain). The timing of therapies is necessarily sequential at the present time and the efficacy of therapies varies over the natural history of the cancer and between patients. For example, bone-targeted therapy is administered in parallel with other therapies. Further, immunotherapy appears to have the most benefit in men with low tumour burden.

Currently, there are six agents which have demonstrated efficacy in phase III clinical trial for metastatic CRPC (Table 1). This has brought greater optimism to patients and clinicians facing this progressive disease. While none of these new agents are curative, they each prolong median survival by several months and reduce death rates by $\sim 30 \%$. As more active agents become available, new challenges arise with respect to timing, sequencing, and biologically rational combinatorial cotargeting strategies evaluating these agents. Cost-benefit and appropriate selection of patients are also issues which need to be addressed. A better understanding of the biological drivers of resistance may guide combination strategies to be tested in future studies and also aid in trial design.

\section{ONGOING AND FUTURE CLINICAL TRIALS}

The complexity of the evolving treatment landscape and many new therapies emerging present challenges to conduct future large scale randomized control trials. Table 2 lists selected ongoing phase III trials in CRPC. Recent phase III trials have highlighted the difficulty of selecting appropriate surrogate endpoints. ${ }^{32}$ Clinical trial outcomes may need to be customized to the therapeutic agent being studied. Further, there now exist many patients who have received multiple prior treatments; the effect on resistance to subsequent treatments is 


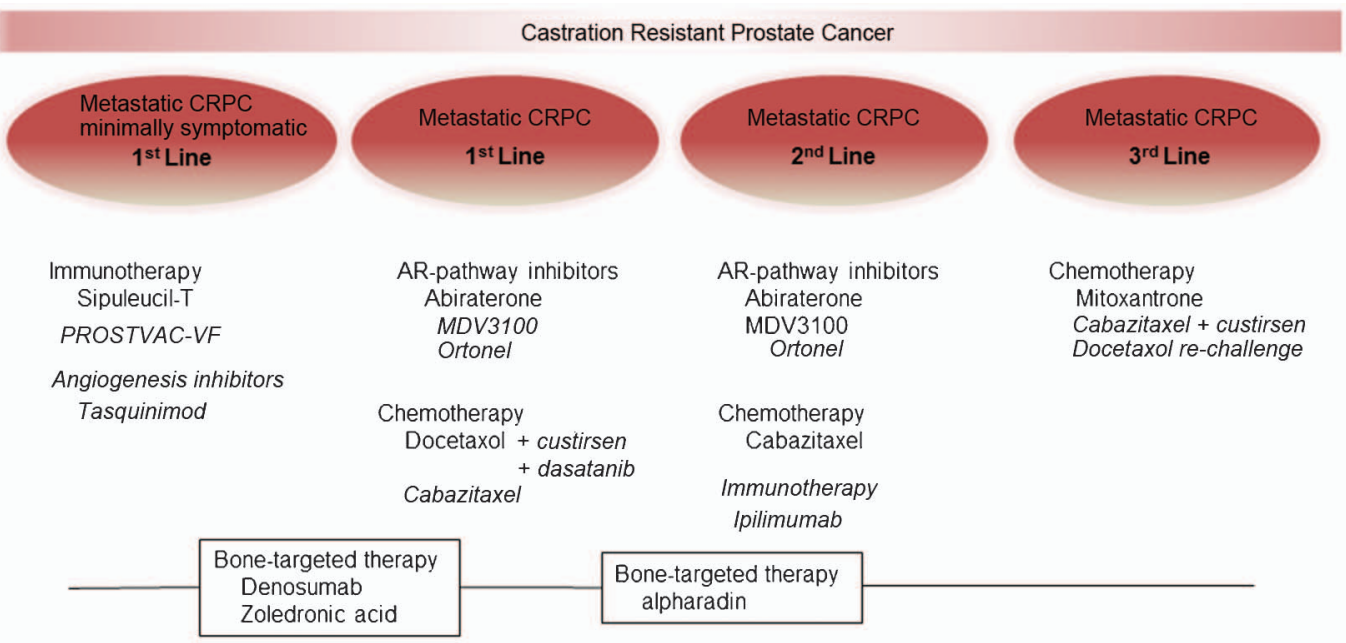

Figure 1 The evolving landscape of treatment options for metastatic CRPC. Therapies currently approved are shown in regular font; those in ongoing phase III trials are shown in italic font. AR, androgen receptor; CRPC, castrate-resistant prostate cancer.

currently poorly understood. Retrospective analyses of large trials may yield pertinent information from which to tailor future trial design as well as patient therapy. ${ }^{33}$ Similarly, registration trials may become an increasingly important source of information to answer questions of sequencing and patient selection.

One of the large unmet needs in CRPC is the identification of biomarkers to predict response and tailor therapy for patients. As well as selecting patients to minimize side effects and those who will benefit, the cost of new targeted therapies may necessitate further patient selection. Prospective identification, validation and integration of biomarkers into clinical trials will help guide treatment options and establish surrogate endpoints to aid in future trial design. A full review of biomarkers in CRPC is beyond the scope of this text, but these are now incorporated into many ongoing trials. Circulating tumour cells and gene fusion signatures represent some of the current biomarkers being examined. ${ }^{34}$

The remainder of this review will highlight the different classes of therapies which are in clinical evaluation (phase II or III trials only). A schematic of targets in CRPC is presented in Figure 2. We will discuss tumour cell-targeted therapies, such as microtubule inhibitors, AR-directed therapy, stress-response inhibitors and targets of the tumour microenvironment such as angiogenesis inhibitors, immunotherapy and bone-targeted agents.

\section{MICROTUBULE INHIBITORS}

Taxanes function by stabilizing the dynamic polymerisation of microtubules in rapidly dividing cancer cells. Another more recently discovered mechanism of action in prostate cancer involves the inhibition of AR localisation and signaling. ${ }^{35}$ As a result of targeting rapidly dividing cells, common side effects of these agents include nausea, diarrhea, alopecia and cytopenias.

Docetaxel was the first chemotherapeutic to demonstrate a survival benefit in CRPC. ${ }^{9,36}$ The TAX327 study established docetaxel every 3 weeks plus daily prednisone as the standard of care for CRPC. ${ }^{9}$ Updated survival results indicated a median survival of 19.2 months in the docetaxel q3 weekly plus prednisose arm versus 17.8 months in the weekly docetaxel arm plus prednisone versus 16.3 months in the mitoxantrone/prednisone arm. ${ }^{36}$ Re-challenging patients with docetaxel after recurrence of CRPC has also demonstrated some clinical success. ${ }^{37,38}$

The TROPIC study randomized men who had progressed either during or after docetaxel to receive cabazitaxel plus prednisone versus mitoxantrone plus prednisone. ${ }^{39}$ With a similar mechanism of action to docetaxel, cabazitaxel did improve OS by a median of 2.4 months. Cabazitaxel had a higher rate of adverse effects, particularly myelosupression, though even mitoxantrone adverse events were higher than prior trials. ${ }^{9,10}$ Side effects of neutropenia and diarrhea were common $(82 \%$

Table 2 Selected ongoing phase III trials in metastatic castrate-resistant prostate cancer (source: http://www.clinicaltrials.gov)

\begin{tabular}{|c|c|c|c|c|}
\hline Trial & Disease state & Trial arms & Estimated completion date & Primary outcome \\
\hline PREVAIL & First-line, asymptomatic & Enzalutamide vs. placebo & Sep 2014 & OS, PFS \\
\hline PROSPECT & First-line, asymptomatic & PROSTVAC+GM-CSF vs. PROSTVAC+GM-CSF placebo vs. placebo & Aug 2015 & OS \\
\hline CA-184-095 & First-line, asymptomatic & Ipilimumab vs. placebo & Jan 2016 & OS \\
\hline NCT0123431 & First-line, asymptomatic & Tasquimod vs. placebo & Jan 2016 & OS \\
\hline FIRSTANA & First-line & Cabazitaxel+prednisone vs. DP & Dec 2017 & OS \\
\hline C21004 & First-line & Ortonel+prednisone vs. prednisone & Jun 2014 & rPFS, OS \\
\hline SYNERGY & First-line & DP vs. DP+custirsen & Dec 2013 & OS \\
\hline READY & First-line & dasatinib+docetaxel+prednisone vs. docetaxel+prednisone & Feb 2013 & OS \\
\hline PROSELICA & Second-line & Cabazitaxel + prednisone at $20 \mathrm{mg} \mathrm{m}^{-2}$ vs. $25 \mathrm{mg} \mathrm{m}^{-2}$ & Sep 2017 & OS \\
\hline CA-184-043 & Second-line & Ipilimumab vs. placebo & Sep 2013 & OS \\
\hline C21005 & Second-line & Ortonel+prednisons vs. prednisone & Oct 2013 & OS \\
\hline AFFINITY & Second-line & Cabazitazel+prednisone+custirsen vs. cabazitazel+ prednisone & Dec 2015 & OS \\
\hline COMET-1 & Third-line & Cabozantinib vs. prednisone & Mar 2014 & OS \\
\hline
\end{tabular}

Abbreviations: DP, doxetaxol+prednisone; GM-CSF, granulocyte-macrophage colony-stimulating factor; OS, overall survival; PFS, progression-free survival; rPFS, radiographic progression-free survival. 


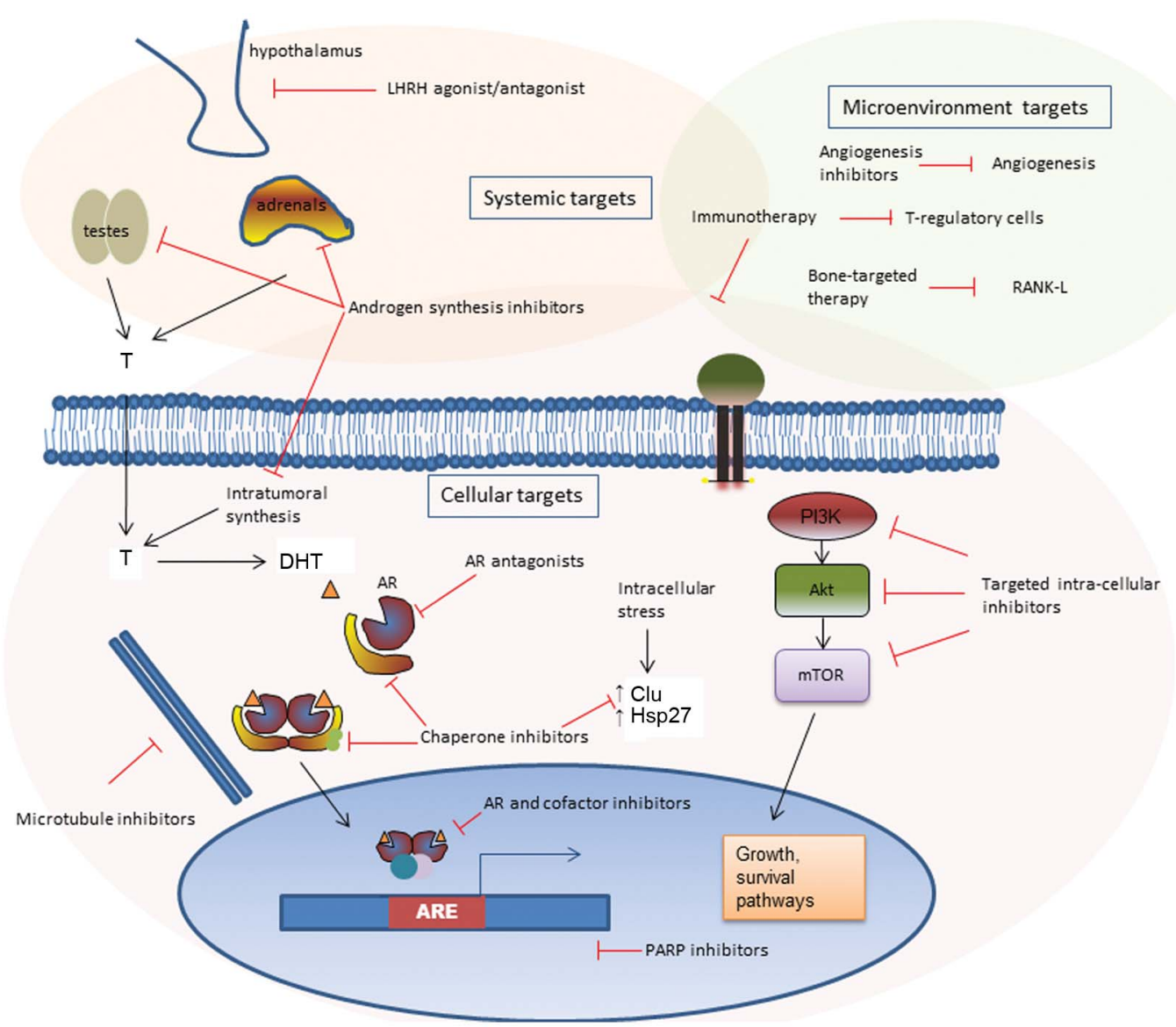

Figure 2 Schematic of therapeutic targets for castrate-resistant prostate cancer. AR, androgen receptor; ARE, androgen-responsive elements; DHT, dihydrotestosterone; PARP, poly-ADP ribose polymerase.

versus $58 \%$ and $6 \%$ versus $<1 \%$ cabazitaxel versus mitoxantrone). Significantly, 28 patients ( $8 \%$ ) in the cabazitaxel group had febrile neutropenia during the study versus $5(1 \%)$ patients in the mitoxantrone arm. Two phase III trials are ongoing: FIRSTANA assesses cabazitaxel prior to docetaxel, while PROSELICA evaluates a lower dose $\left(20 \mathrm{mg} \mathrm{m}^{-2}\right.$ versus $25 \mathrm{mg} \mathrm{m}^{-2}$ ) in men treated with prior docetaxel.

Epothilones also target microtubules through a different mechanism of action. Patupilone in a phase II study recently demonstrated anti-tumour activity and safety as second-line therapy. ${ }^{40}$ The oral synthetic epothilone, ixabepilone, demonstrated better activity in chemo-naive patients ${ }^{41-43}$ compared to using second-line therapy, but has not been advanced to phase III trials.

\section{AR-TARGETED THERAPY}

Recent decades of research have found the AR to remain an enduring target throughout the progression of prostate cancer. More recent research suggests that it continues to remain active in resistance to the newer AR-targeted therapies enzalutamide and abiraterone. ${ }^{23,24}$ The AR gene is encoded on Xq11-12 and consists of eight exons which correspond to different parts of the modular protein. The receptor is similar to other nuclear-binding receptors, and has several components: the regulatory $\mathrm{N}$-terminal domain, the DNA-binding domain and the carboxy-terminal ligand-binding domain.

Enzalutamide (MDV3100) is a more potent AR ligand-binding domain antagonist than the previous drugs in its class such as bicalutamide. It functions by inhibiting binding of ligand (DHT) to the AR, thereby inhibiting nuclear translocation and binding of the AR to
DNA. $^{44}$ The use of enzalutamide in men with CRPC post-chemotherapy showed an improved median OS of 18.4 months (95\% CI: 17.3 to not yet reached) compared to 13.6 months (95\% CI: 11.3-15.8) in the placebo arm. ${ }^{45}$ Side effects of fatigue diarrhea and hot flashes were higher in the enzalutamide group. Five of the 800 patients in the treatment arm experienced seizures, most of whom had a pre-existing disposition to seizures. The PREVAIL trial is ongoing in asymptomatic men with nonmetastatic CRPC evaluating enzalutamide as first-line therapy.

Several novel AR inhibitors are currently in various stages of development. ${ }^{46}$ ARN-509 is an AR inhibitor in phase II trials which is structurally similar to enzalutamide with reportedly greater in vivo activity. ${ }^{47}$ ARN-509 inhibits nuclear translocation of the AR as well as AR binding to androgen-responsive elements. Further, inhibitors of the $\mathrm{N}$-termimus domain of the AR are now in development. This strategy is appealing given the recent evidence suggesting the importance of androgen splice variants in enzalutamide resistance. ${ }^{24}$ Splice variants lack the ligand-binding domain and appear to constitutively activate AR-related genes. EPI-001 is a small-molecular inhibitor which specifically targets the N-terminus domain and does not block ligand binding. ${ }^{48}$ Other investigational methods to abrogate AR-driven growth in CRPC cells include antisense approaches, and second-site AR antagonists, such as targeting the BF-3 domain of the AR. ${ }^{49,50}$

\section{ANDROGEN SYNTHESIS INHIBITION}

The inhibition of steroidogenic enzymes in prostate cancer dates back to the use of ketoconazole in advanced prostate cancer almost 30 years 
ago. ${ }^{51}$ Through blockade of the cytochrome $\mathrm{p} 450$ enzyme, there is a decrease in testosterone (and DHT) ligand available to the AR in prostate cancer cells. The CYP450 enzyme functions both as a lyase and a hydroxylase on subsequent steps of the biosynthetic pathway of androgens. When used alongside castration, these inhibitors additionally block both adrenal and intratumoural androgen production.

Abiraterone now has phase III data indicating its efficacy both following chemotherapy and in chemo-naive patients with CRPC. The COU-AA-301 study randomized 1195 men following chemotherapy $2: 1$ to receive abiraterone $1000 \mathrm{mg}$ daily plus $5 \mathrm{mg}$ BID prednisone versus $5 \mathrm{mg}$ b.i.d prednisone. ${ }^{52}$ An improvement in median OS of 3.9 months was seen with 12.8 month of median follow-up. Mineralocorticoid-related adverse events such as fluid retention, hypertension and hypokalemia were more common in the abiraterone group. The recently published COU-AA-302 study randomized 1088 chemo-naive men with asymptomatic or mildly symptomatic metastatic CRPC 1:1 to abiraterone plus prednisone or prednisone. The coprimary endpoints were radiographic progression-free survival (PFS) and OS. With a median follow-up of 22.2 months, the results favoured abiraterone. Median OS and radiographic PFS were not yet reached in the treatment group, with a hazard ratio of $0.75(95 \% \mathrm{CI}$ : $0.61-0.93, P=0.0097)$ and 0.53 (95\% CI: $0.45-0.62, P<0.0001$ ), respectively. ${ }^{15}$ Time to PSA progression (11.1 months versus 5.6 months), time to chemotherapy (25.2 months versus 18.8 months) and time to opiate use (not reached versus 23.7 months) were all significantly better in the abiraterone treated group. As an oral medication which is better tolerated compared to chemotherapy, this may signal the decline of chemotherapy as first-line treatment of CRPC.

Several other CYP17-20 inhibitors are under evaluation. Orteronel (TAK-700) is a more selective, but less potent 17,20-lyase activity inhibitor compared to abiraterone. ${ }^{53}$ Two phase III trials are currently evaluating orteronel prior to and subsequent to chemotherapy, respectively (NCT01193244 and NCT01193257). Galeterone (TOK-001) is another novel agent in the pipeline. It also acts as a CYP17-20 lyase inhibitor, which uniquely also appears to increase AR degradation. ${ }^{54,55}$ Promising results were seen in the phase I trial, with both PSA and radiological responses present. A phase II study in both treatment naive and CRPC patients is now underway. VT464 is another novel Cyp450 inhibitor which has specificity for the lyase function of this dual hydroxylase/lyase enzyme. With less hydroxylase inhibition, there is less cortisol suppression and subsequently less mineralocorticoid suppression. This specificity is hoped to lead to less mineralocorticoid-related side effects.

\section{CELL-SIGNALLING INHIBITORS}

Preclinical research has identified molecular pathways activated in CRPC and led to several new targeted therapies under investigation for CRPC patients. Several intracellular and receptor transduction pathway inhibitors are being evaluated in phase II trials. A combination approach with these inhibitors is favoured in order to leverage synergistic activity while maintaining minimal toxicity. Preclinical studies suggest a synergist effect through dual targeting of AR and signal transduction pathways. ${ }^{25,56}$ Everolimus is an inhibitor of mTOR, a central energy signalling pathway molecule, which is being evaluation with bicalutamide, docetaxel and bevacizumab in phase II trials. PI-3 kinase, Akt and MAPK inhibitors are currently in the pipeline for use in cotargeting strategies in CRPC.

Dasatinib and saracatinib (AZD0530) are two Src inhibitors which have completed phase II trials. Preclinical studies indicate Src tyrosine kinases function downstream of membrane receptors and are associated the prostate cancer progression through various mechanisms, including proliferation, invasion and interactions with the AR. ${ }^{57-59}$ Further, Src signalling plays a role in regulating bone turnover in prostate cancer. ${ }^{60}$ Dasatinib is a small-molecule multityrosine kinase inhibitor of several signaling proteins, including receptor tyrosine kinases, Src family kinases, Bcr-Abl, c-Kit, PDGFR and ephrins. ${ }^{61}$ Dasatinib, along with sunitinib, is currently being evaluated in combination with abiraterone in phase II clinical trials. In phase I/II trials evaluating dasatinib in combination with docetaxel, $30 \%$ of patients had disappearance of lesions on bone scan and $57 \%$ of patients had a durable PSA response in the phase I/II trial. ${ }^{62}$ In phase II monotherapy trials in men prior to chemotherapy, no responses were seen, but there was a lack of progression in $43 \%$ of patients at 12 weeks. ${ }^{63}$ Common adverse events include fatigue, nausea, diarrhea, headache and anorexia. ${ }^{64}$ Results of the phase III READY trial of dasatinib in addition to standard docetaxol in metastatic CRPC recently presented also showed no benefit to OS. ${ }^{65}$

\section{STRESS-RESPONSE INHIBITORS}

Molecular chaperones play central roles in stress responses by maintaining protein homeostasis and regulating prosurvival signalling and transcriptional networks. Chaperone proteins bind and stabilize intracellular proteins, protecting against stress, misfolding and aggregation. They also facilitate intracellular transport and nuclear translocation. ${ }^{30}$ Two stress-activated cytoprotective chaperones, clusterin and Hsp27 are targets in current clinical trials of CRPC.

Custirsen (OGX-011) is an antisense oligonucleotide against the clusterin gene on $8 \mathrm{p} 21-\mathrm{p} 12$. Clusterin functions as a cytoprotective chaperone and is upregulated in CRPC. A phase II trial in 82 patients of custirsen plus docetaxel and prednisone versus docetaxel and prednisone demonstrated a 6.9 months improvement in median survival. ${ }^{66}$ A phase III trial is ongoing, with results expected in 2014.

Heat shock protein-27 (Hsp27) is another abundant stress-induced chaperone protein involved with the AR and treatment resistance. ${ }^{67,68}$ OGX-427 is a second generation antisense oligonucleotide against Hsp27 in phase II trials in combination with abiraterone in metastatic CRPC and as second-line treatment in combination with prednisone in patients with metastatic CRPC.

Poly-ADP ribose polymerase (PARP) inhibitors represent a different class of therapeutics and include veliparib and olaparib. The enzyme poly-ADP ribose polymerase is responsible for repairing single strand breaks in DNA. Inhibition of this enzyme leads to alterations in the ability of DNA replication to occur, causing cell death. ${ }^{69}$ Phase II studies underway attempt to assess their efficacy in patients with ETS gene fusions.

\section{ANGIOGENESIS INHIBITORS}

Several classes of angiogenesis inhibitors exist, targeting vascular endothelial growth factor (VEGF) and related tyrosine kinase pathways, endothelins and other novel targets. Angiogenesis inhibitors have now become standard therapies for several tumour sites, including renal cell carcinoma and colon cancer. However, phase III trials of anti-angiogenic agents in prostate cancer to date have all been negative. This may be related to the typical difference in size and vascularisation: clinically, renal cell carcinomas often grow into large, heavily vascularized tumours, while prostate cancer more commonly spreads extensively before having an a single large tumour site.

Phase III trials of the VEGF inhibitors, bevacizumab and aflibercept, in combination with docetaxel, were negative. As first-line therapy, bevacizumab in combination with docetaxel and prednisone provided no OS benefit, though there was an improvement in progression-free survival (PFS). ${ }^{13}$ The result of a similar study for aflibercept has not yet been published, but also did not show benefit in the primary outcome 
of OS. A phase III trial of the tyrosine kinase inhibitor sorafenib as first-line therapy was also negative. ${ }^{70}$

A similar disappointing story is seen reviewing endothelin antagonists. Endothelins are a family of peptides expressed mainly in endothelial cells throughout the body. Endothelin-1 is the most abundant and has higher serum levels in prostate cancer and binds to the endothelin-A receptor. Through various cell-signalling cascades, it is involved with angiogenesis, as well as prostate cancer cell proliferation and invasion. ${ }^{71}$ Zibotentan (ZD5054) and atrasentan are two endothelin-1 receptor antagonists with completed phase III clinical trials. Zibotentan in asymptomatic or mildly symptomatic men with metastatic CRPC did not demonstrate any survival benefit. ${ }^{72}$ Atrasentan also recently demonstrated no survival benefit in combination with docetaxel as first-line therapy or as monotherapy in metastatic CRPC.

Tasquinimod is an oral anti-angiogenic drug still in phase III trials. However, it has a different mechanism of action. Tasquinimod disrupts crosstalk within the tumour microenvironment by modulating HDAC4 and also targets S100A9. ${ }^{73}$ Phase II results demonstrated in minimally symptomatic metastatic disease a median PFS of 7.6 months versus 3.3 months in the placebo arm $(P=0.0042) .{ }^{74}$ Grade 3-4 adverse events were common (40\%) compared to placebo (10\%), though many were asymptomatic elevation of laboratory parameters. Four percent of patients in the treatment arm versus none in the placebo experienced a deep vein thrombosis.

Cabozantinib (XL184) is a dual c-met and VEGF-receptor inhibitor. Phase II results demonstrated at 12 weeks that $68 \%$ of patients had an improvement on bone scan, with $12 \%$ having complete remission. ${ }^{27}$ The improvement in PFS was notable, with a median PFS of those receiving treatment of 23.9 weeks versus 5.9 weeks in placebo, though randomisation was halted early in the trial due to the benefit seen, with only 31 patients randomized. ${ }^{27}$ Newer angiogenesis inhibitors currently in phase II trials include TRC-105, a chimeric monoclonal antibody against CD105 (endoglin) which is a receptor overexpressed on proliferating endothelium, ${ }^{75}$ and the VEGF inhibitors Pazopanib and Dovitinib (http://www.clinicaltrials.gov).

\section{IMMUNOTHERAPY}

Immunotherapy now has level one evidence to support its use in CRPC. In the IMPACT study, there was an OS benefit of 4.1 months with sipuleucil- $\mathrm{T}$ in men with asymptomatic or minimally symptomatic metastatic prostate cancer. ${ }^{76}$ However, no difference in PFS was found. The treatment consists of re-infusion of activated autologous peripheral blood monocytes and antigen presenting cells exposed ex vivo to the fusion protein of prostatic acid phosphatase and granulocyte-macrophage colony-stimulating factor (GM-CSF). The most common adverse effects of treatment were infusion-related and included chills, fever, nausea and fatigue. ${ }^{76}$

Immunotherapy does not directly target the tumour cells, but works by priming the patient's own immune system. It appears from analyses of the clinical trials to date that patients with a lower burden of disease are more likely to benefit, a finding not unique to prostate cancer. ${ }^{77}$ One potential benefit of targeting the host instead of the tumour may be a durable effect on the rate of growth of the tumour as the immune systems is primed against tumour antigens. This has yet to be definitively identified; at least no detrimental effect on the effectiveness of subsequent targeted treatments has been found. ${ }^{76}$ However, the lack of PSA response or other objective response to therapy makes identification of subsets of patients who may better respond to this costly therapy challenging.

Another immunotherapy currently under study is the vaccine PROSTVAC-VF. This vaccine includes transgenes for PSA as well as three costimulatory molecules: B7.1, leukocyte function-associated antigen-3 and intercellular adhesion molecule- $1 .^{78}$ Inclusion of the costimulatory genes is understood to enhance cell mediated immunity and memory to the weakly immunogenic PSA. The first priming injection uses a recombinant vaccinia platform. Subsequently, booster monthly injections use the fowlpox vaccine platform to avoid neutralizing antibodies to vaccinia which may develop. Similar to the IMPACT study, a phase II study showed an OS benefit with no PFS benefit. ${ }^{79}$ An ongoing phase III study three-arm study compares the OS in men with minimally symptomatic metastatic prostate cancer treated with PROSTVAC \pm GM-CSF versus placebo. The third arm including GM-CSF was included as an adjuvant to boost the immune response based on preclinical studies. ${ }^{80}$ GVAX is a whole-cell vaccine against PC3 and LNCaP cell lysate which had two phase III trials terminated early due to absence of benefit and an increased incidence of deaths in the treatment arm, respectively. ${ }^{81}$

Ipilimumab is a fully human monoclonal antibody with a unique mechanism of action. It targets CTLA-4, an important negative regulatory receptor in T cells. By blocking CTLA-4, the homeostatic negative feedback on $\mathrm{T}$ regulatory cells which the immune system establishes to avoid autoimmunity is relaxed. This effectively decreases some of the immune system's tolerance against tumour antigens which usually develops. This approach has demonstrated significant benefit in advanced melanoma. ${ }^{82}$ Two randomized trials comparing ipilimumab versus placebo prior to and after chemotherapy are underway. ${ }^{81}$ Along with its unique mechanism of action are unique side effects, which include severe rash ( $\sim 50 \%$ of cases), enterocolitis (grades $3-4$ in up to $16 \%$ of cases), hypophysitis ( $\sim 5 \%$ of cases) and hepatitis ( $<5 \%$ of cases). ${ }^{82}$

A similar strategy is under investigation targeting the programmed death-1 pathway. Programmed death-1 is an inhibitory receptor expressed on T cells. By targeting this receptor, the immune system loses some negative autoregulation and is thought to be more active against tumour antigens. A monoclonal antibody against programmed death-1 has demonstrated efficacy in several advanced stage cancers, and clinical trials in prostate cancer are now commencing. ${ }^{83}$ This approach is hoped to have fewer side effects than targeting CTLA4 given its greater specificity for the tumour microenvironment.

\section{BONE-TARGETED AGENTS}

The propensity for prostate cancer to metastasize to the bone and the side effects of androgen deprivation highlight the importance of concomitant bone therapy for men with CRPC. Lifestyle changes to decrease bone loss, including weight loss, exercise, smoking cessation and moderate alcohol intake, should be combined with calcium supplementation and appropriate pharmacotherapy.

Several pharmacotherapies now have evidence for their use in prevention of skeletal related events in men with CRPC. The use of the bisphosphonate zoledronic acid prevents skeletal-related events, but has not demonstrated any survival benefit. ${ }^{8,12}$ Denosumab is a monoclonal antibody against RANK-L, a key signalling molecule in the activation of osteoclasts. It appears to delay the appearance of bone metastasis in patients at risk, ${ }^{84}$ but no difference in OS has been noted in several large trials. It has superior potency and greater reduction in skeletal-related events compared to zoledronic acid. ${ }^{85}$ The side effects are also generally greater with denosumab, though both can cause hypocalcemia and osteonecrosis of the jaw. Osteonecrosis of the jaw occurs particularly in patients with known dental problems.

Radiopharmaceuticals have been available for several decades to treat metastatic bone pain. Both Rhenium-186 and Samarium-135 have demonstrated improved bone pain in men with metastatic 
CRPC in small randomized trials. ${ }^{86,87}$ Strontium-89 as a calcium mimetic with strong propensity for bone, is another radiopharmaceutical studied in CRPC. ${ }^{88,89}$ A British phase III trial of 757 patients evaluating the combination of $\mathrm{Sr}^{89}$ with docetaxel and prednisolone versus docetaxel and prednisolone plus zoledronic acid or $\mathrm{Sr}^{89}$ is ongoing, with accrual closed. Overall, the broad utilisation of these radiopharmaceuticals remains low in part due to side effects. The betaparticles emitted can damage the bone marrow, causing haematological toxicity in patients who often already have anemia.

Radium-223 chloride is a new radiopharmaceutical which emits alpha radiation from the decay of radium. As a calcium mimetic, it has a natural propensity for the bone; the short depth of penetration and the high energy of alpha radiation which it releases allow a high dose to the tumour with relative sparing of the bone marrow. In clinical trials to date, it has demonstrated an improvement in OS in patients with painful bone metastases. ${ }^{90,91}$ The ALSYMPCA trial randomized 922 men with bone metastases $2: 1$ to receive Radium-223 versus placebo injections. ${ }^{92}$ This included men who had received chemotherapy and those who had not. The trial was stopped at the interim analysis as a survival benefit was noted in favour of Radium-223, with a hazard ratio for OS of 0.70 . There were few side effects; grade 3 or 4 haematological toxicities did not differ significantly in treatment and placebo arms, respectively (neutropenia $1.8 \%$ versus $0.8 \%$ and thrombocytopenia $4 \%$ versus $2 \%$ ). In a separate phase II dose finding trial, a dose-dependent improvement in survival was found, highlighting that a survival benefit can be reached through targeting bone metastases. ${ }^{91}$

\section{SUMMARY}

There continues to be exciting improvements in the treatment of CRPC, but many challenges remain. It now appears that CRPC continues to be sensitive to AR pathway inhibition, though resistance to AR directed therapy invariably develops. The role of cotargeted pathways in addition to anti-AR therapy continues to be pursued in preclinical research. Future trials will need to evaluate the ability of these cotargeting strategies to delay the development of resistance. Further, the weight of recent success brings new challenges of optimally selecting treatments to maximize patient benefit, while minimizing toxicity and cost. Therefore, a continued integration of knowledge from ongoing clinical trials and the laboratory is required to further advance the evolving treatment landscape of CRPC.

\section{COMPETING FINANCIAL INTERESTS}

The University of British Columbia has submitted patent applications, listing Dr. Gleave as inventor, on the anti-cancer drugs OGX-011 and OGX-427 described in this paper. This IP has been licensed to OncoGenex Technologies, a Vancouver-based biotechnology company that Dr. Gleave has founding shares in.

1 Huggins $C$, Hodges $C$. The effect of castration, of estrogen and of androgen injection on serum phosphatases in metastatic carcinoma of the prostate. Cancer Res 1941; 1: 293-7.

2 Scher HI, Halabi S, Tannock I, Morris M, Sternberg CN et al. Design and end points of clinical trials for patients with progressive prostate cancer and castrate levels of testosterone: recommendations of the Prostate Cancer Clinical Trials Working Group. J Clin Oncol 2008; 26: 1148-59.

3 Hirst CJ, Cabrera C, Kirby M. Epidemiology of castration resistant prostate cancer: a longitudinal analysis using a UK primary care database. Cancer Epidemio/ 2012; 36: e349-53.

4 Kirby M, Hirst C, Crawford ED. Characterising the castration-resistant prostate cancer population: a systematic review. Int J Clin Pract 2011; 65: 1180-92.

5 Smith MR, Kabbinavar F, Saad F, Hussain A, Gittelman MC et al. Natural history of rising serum prostate-specific antigen in men with castrate nonmetastatic prostate cancer. J Clin Oncol 2005; 23: 2918-25.
6 Fast Stats: An interactive tool for access to SEER cancer statistics. Surveillance Research Program, National Cancer Institute. http://seer.cancer.gov/faststats.

7 Smith MR, Cook R, Lee KA, Nelson JB. Disease and host characteristics as predictors of time to first bone metastasis and death in men with progressive castration-resistant nonmetastatic prostate cancer. Cancer 2011; 117: 2077-85.

8 Ernst DS, Tannock IF, Winquist EW, Venner PM, Reyno L et al. Randomized, doubleblind, controlled trial of mitoxantrone/prednisone and clodronate versus mitoxantrone/prednisone and placebo in patients with hormone-refractory prostate cancer and pain. J Clin Oncol 2003; 21: 3335-42.

9 Tannock IF, de Wit R, Berry WR, Horti J, Pluzanska A et al. Docetaxel plus prednisone or mitoxantrone plus prednisone for advanced prostate cancer. N Engl J Med 2004; 351: 1502-12.

10 Petrylak DP, Tangen CM, Hussain MH, Lara PN Jr, Jones JA et al. Docetaxel and estramustine compared with mitoxantrone and prednisone for advanced refractory prostate cancer. N Engl J Med 2004; 351: 1513-20.

11 Maximum androgen blockade in advanced prostate cancer: an overview of 22 randomised trials with 3283 deaths in 5710 patients. Prostate Cancer Trialists' Collaborative Group. Lancet 1995; 346: 265-9.

12 Saad F, Gleason DM, Murray R, Tchekmedyian S, Venner P et al. Long-term efficacy of zoledronic acid for the prevention of skeletal complications in patients with metastatic hormone-refractory prostate cancer. J Nat/ Cancer Inst 2004; 96: 879-82.

13 Kelly WK, Halabi S, Carducci M, George D, Mahoney JF et al. Randomized, doubleblind, placebo-controlled phase III trial comparing docetaxel and prednisone with or without bevacizumab in men with metastatic castration-resistant prostate cancer: CALGB 90401. J Clin Oncol 2012; 30: 1534-40.

14 Inoue T, Segawa T, Kamba T, Yoshimura K, Nakamura E et al. Prevalence of skeletal complications and their impact on survival of hormone refractory prostate cancer patients in Japan. Urology 2009; 73: 1104-9.

15 Ryan CJ, Smith MR, de Bono JS, Molina A, Logothetis CJ et al. Abiraterone in metastatic prostate cancer without previous chemotherapy. N Engl J Med 2013; 368: 138-48.

16 Denmeade SR, Isaacs JT. A history of prostate cancer treatment. Nat Rev Cancer 2002; 2: 389-96.

17 Locke JA, Guns ES, Lubik AA, Adomat HH, Hendy SC et al. Androgen levels increase by intratumoral de novo steroidogenesis during progression of castration-resistant prostate cancer. Cancer Res 2008; 68: 6407-15.

18 Chen CD, Welsbie DS, Tran C, Baek SH, Chen R et al. Molecular determinants of resistance to antiandrogen therapy. Nat Med 2004; 10: 33-9.

19 Koochekpour S. Androgen receptor signaling and mutations in prostate cancer. Asian J Androl 2010; 12: 639-57.

20 Nadiminty N, Gao AC. Mechanisms of persistent activation of the androgen receptor in CRPC: recent advances and future perspectives. World J Urol 2012; 30: 287-95.

21 Kohli M, Qin R, Jimenez R, Dehm SM. Biomarker-based targeting of the androgenandrogen receptor axis in advanced prostate cancer. Adv Urol 2012; 2012: 781459.

22 Beltran H, Yelensky R, Frampton GM, Park K, Downing SR et al. Targeted nextgeneration sequencing of advanced prostate cancer identifies potential therapeutic targets and disease heterogeneity. Eur Urol 2012; pii: S0302-2838(12)01006-8.

23 Mostaghel EA, Marck BT, Plymate SR, Vessella RL, Balk S et al. Resistance to CYP17A1 inhibition with abiraterone in castration-resistant prostate cancer: induction of steroidogenesis and androgen receptor splice variants. Clin Cancer Res 2011; 17: 5913-25.

24 Li Y, Chan SC, Brand LJ, Hwang TH, Silverstein KA et al. Androgen receptor splice variants mediate enzalutamide resistance in castration-resistant prostate cancer cell lines. Cancer Res 2012; 73: 483-9.

25 Carver BS, Chapinski C, Wongvipat J, Hieronymus H, Chen Y et al. Reciprocal feedback regulation of $\mathrm{PI} 3 \mathrm{~K}$ and androgen receptor signaling in PTEN-deficient prostate cancer. Cancer Cell 2011; 19: 575-86.

26 Morris MJ, Kelly WK, Slovin S, Ryan C, Eicher C et al. A phase II trial of bortezomib and prednisone for castration resistant metastatic prostate cancer. J Urol 2007; 178: 2378-83; discussion 2383-4.

27 Smith DC, Smith MR, Sweeney C, Elfiky AA, Logothetis C et al. Cabozantinib in patients with advanced prostate cancer: results of a phase II randomized discontinuation trial. J Clin Oncol 2012; 31: 412-9.

28 Blanc V, Nariculam J, Munson P, Freeman A, Klocker $\mathrm{H}$ et al. A role for class 3 semaphorins in prostate cancer. Prostate $2011 ; 71: 649-58$.

29 Zoubeidi A, Chi K, Gleave M. Targeting the cytoprotective chaperone, clusterin, for treatment of advanced cancer. Clin Cancer Res 2010; 16: 1088-93.

30 Zoubeidi A, Gleave M. Small heat shock proteins in cancer therapy and prognosis. Int J Biochem Cell Biol 2012; 44: 1646-56.

31 Dhir R, Ni Z, Lou W, DeMiguel F, Grandis JR et al. Stat3 activation in prostatic carcinomas. Prostate 2002; 51: 241-6.

32 Armstrong AJ, Eisenberger MA, Halabi S, Oudard S, Nanus DM et al. Biomarkers in the management and treatment of men with metastatic castration-resistant prostate cancer. Eur Urol 2012; 61: 549-59.

33 Pond GR, Armstrong AJ, Galsky MD, Wood BA, Leopold L et al. Efficacy of docetaxelbased chemotherapy following ketoconazole in metastatic castration-resistant prostate cancer: Implications for prior therapy in clinical trials. Urol Oncol; e-pub ahead of print 1 May 2012;doi:10.1016/j.urolonc.2012.02.008.

34 Danila DC, Anand A, Sung CC, Heller G, Leversha MA et al. TMPRSS2-ERG status in circulating tumor cells as a predictive biomarker of sensitivity in castration-resistant prostate cancer patients treated with abiraterone acetate. Eur Urol 2011; 60: 897-904.

35 Gan L, Chen S, Wang Y, Watahiki A, Bohrer L et al. Inhibition of the androgen receptor as a novel mechanism of taxol chemotherapy in prostate cancer. Cancer Res 2009; 69: 8386-94. 
36 Berthold DR, Pond GR, Soban F, de Wit R, Eisenberger M et al. Docetaxel plus prednisone or mitoxantrone plus prednisone for advanced prostate cancer: updated survival in the TAX 327 study. J Clin Oncol 2008; 26: 242-5.

37 Caffo O, Pappagallo G, Brugnara S, Caldara A, di Pasquale MC et al. Multiple rechallenges for castration-resistant prostate cancer patients responding to first-line docetaxel: assessment of clinical outcomes and predictive factors. Urology 2012; 79: 644-9.

38 Loriot Y, Massard C, Gross-Goupil M, Di Palma M, Escudier B et al. The interval from the last cycle of docetaxel-based chemotherapy to progression is associated with the efficacy of subsequent docetaxel in patients with prostate cancer. Eur J Cancer 2010; 46: 1770-2.

39 de Bono JS, Oudard S, Ozguroglu M, Hansen S, Machiels JP et al. Prednisone plus cabazitaxel or mitoxantrone for metastatic castration-resistant prostate cance progressing after docetaxel treatment: a randomised open-label trial. Lancet 2010; 376: 1147-54.

40 Chi KN, Beardsley E, Eigl BJ, Venner P, Hotte SJ et al. A phase 2 study of patupilone in patients with metastatic castration-resistant prostate cancer previously treated with docetaxel: Canadian Urologic Oncology Group study P07a. Ann Oncol 2012; 23: 53-8.

41 Rosenberg JE, Galsky MD, Rohs NC, Weinberg VK, Oh WK et al. A retrospective evaluation of second-line chemotherapy response in hormone-refractory prostate carcinoma: second line taxane-based therapy after first-line epothilone-B analog ixabepilone (BMS-247550) therapy. Cancer 2006; 106: 58-62.

42 Hussain M, Tangen CM, Lara PN Jr, Vaishampayan UN, Petrylak DP et al. Ixabepilone (epothilone B analogue BMS-247550) is active in chemotherapy-naive patients with hormone-refractory prostate cancer: a Southwest Oncology Group trial S0111. J Clin Oncol 2005; 23: 8724-9.

43 Galsky MD, Small EJ, Oh WK, Chen I, Smith DC et al. Multi-institutional randomized phase II trial of the epothilone B analog ixabepilone (BMS-247550) with or without estramustine phosphate in patients with progressive castrate metastatic prostate cancer. J Clin Oncol 2005; 23: 1439-46.

44 Tran C, Ouk S, Clegg NJ, Chen Y, Watson PA et al. Development of a second-generation antiandrogen for treatment of advanced prostate cancer. Science 2009; 324: 787-90.

45 Scher HI, Fizazi K, Saad F, Taplin ME, Sternberg CN et al. Increased survival with enzalutamide in prostate cancer after chemotherapy. N Eng/ J Med 2012; 367: 1187-97.

46 Shen HC, Shanmugasundaram K, Simon NI, Cai C, Wang H et al. In silico discovery of androgen receptor antagonists with activity in castration resistant prostate cancer. $\mathrm{Mol}$ Endocrinol 2012; 26: 1836-46.

47 Clegg NJ, Wongvipat J, Joseph JD, Tran C, Ouk S et al. ARN-509: a novel antiandrogen for prostate cancer treatment. Cancer Res 2012; 72: 1494-503.

48 Andersen RJ, Mawji NR, Wang J, Wang G, Haile S et al. Regression of castraterecurrent prostate cancer by a small-molecule inhibitor of the amino-terminus domain of the androgen receptor. Cancer Cell 2010; 17: 535-46.

49 Grosdidier S, Carbo LR, Buzon V, Brooke G, Nguyen P et al. Allosteric conversation in the androgen receptor ligand-binding domain surfaces. Mol Endocrinol 2012; 26: 1078-90.

50 Joseph JD, Wittmann BM, Dwyer MA, Cui H, Dye DA et al. Inhibition of prostate cance cell growth by second-site androgen receptor antagonists. Proc Natl Acad Sci USA 2009; 106: 12178-83.

51 Trachtenberg J, Halpern N, Pont A. Ketoconazole: a novel and rapid treatment for advanced prostatic cancer. J Urol 1983; 130: 152-3.

52 de Bono JS, Logothetis CJ, Molina A, Fizazi K, North S et al. Abiraterone and increased survival in metastatic prostate cancer. N Engl J Med 2011; 364: 1995-2005.

53 Yamaoka M, Hara T, Hitaka T, Kaku T, Takeuchi T et al. Orteronel (TAK-700), a nove non-steroidal 17,20-lyase inhibitor: effects on steroid synthesis in human and monkey adrenal cells and serum steroid levels in cynomolgus monkeys. J Steroid Biochem $\mathrm{Mol}$ Biol 2012; 129: 115-28.

54 DeVore NM, Scott EE. Structures of cytochrome P450 17A1 with prostate cancer drugs abiraterone and TOK-001. Nature 2012; 482: 116-9.

55 Salvador JA, Carvalho JF, Neves MA, Silvestre SM, Leitao AJ et al. Anticancer steroids: linking natural and semi-synthetic compounds. Nat Prod Rep 2013; 30: 324-74.

56 Schayowitz A, Sabnis G, Njar VC, Brodie AM. Synergistic effect of a nove antiandrogen, VN/124-1, and signal transduction inhibitors in prostate cancer progression to hormone independence in vitro. Mol Cancer Ther 2008; 7: 121-32.

57 Kung HJ, Evans CP. Oncogenic activation of androgen receptor. Urol Oncol 2009; 27 48-52.

58 Lee LF, Louie MC, Desai SJ, Yang J, Chen HW et al. Interleukin-8 confers androgenindependent growth and migration of LNCaP: differential effects of tyrosine kinases Src and FAK. Oncogene 2004; 23: 2197-205.

59 Cai J, Zhang S, Zheng M, Wu X, Chen J et al. Design, synthesis, and in vitro antiproliferative activity of novel Dasatinib derivatives. Bioorg Med Chem Let 2012; 22: 806-10.

60 Yang JC, Bai L, Yap S, Gao AC, Kung HJ et al. Effect of the specific Src family kinase inhibitor saracatinib on osteolytic lesions using the PC-3 bone model. Mol Cancer The 2010; 9: 1629-37.

61 Gnoni A, Marech I, Silvestris N, Vacca A, Lorusso V. Dasatinib: an anti-tumour agent via Src inhibition. Curr Drug Targets 2011; 12: 563-78.

62 Araujo JC, Mathew P, Armstrong AJ, Braud EL, Posadas E et al. Dasatinib combined with docetaxel for castration-resistant prostate cancer: results from a phase 1-2 study. Cancer 2012; 118: 63-71

63 Yu EY, Wilding G, Posadas E, Gross M, Culine S et al. Phase II study of dasatinib in patients with metastatic castration-resistant prostate cancer. Clin Cancer Res 2009 15: 7421-8.

64 Yu EY, Massard C, Gross ME, Carducci MA, Culine S et al. Once-daily dasatinib: expansion of phase II study evaluating safety and efficacy of dasatinib in patients with metastatic castration-resistant prostate cancer. Urology 2011; 77: 1166-71.
65 Araujo JC, Trudel GC, Saad F, Armstrong AJ, Yu EY et al. Overall survival (OS) and safety of dasatinib/docetaxel versus docetaxel in patients with metastatic castrationresistant prostate cancer ( $\mathrm{mCRPC}$ ): Results from the randomized phase III READY trial. J Clin Oncol 2013; 31(Suppl 6): abstr LBA8.

66 Saad F, Hotte S, North S, Eigl B, Chi K et al. Randomized phase II trial of Custirsen (OGX-011) in combination with docetaxel or mitoxantrone as second-line therapy in patients with metastatic castrate-resistant prostate cancer progressing after first-line docetaxel: CUOG trial P-06c. Clin Cancer Res 2011; 17: 5765-73.

67 Zoubeidi A, Zardan A, Wiedmann RM, Locke J, Beraldi E et al. Hsp27 promotes insulin-like growth factor-I survival signaling in prostate cancer via p90Rskdependent phosphorylation and inactivation of BAD. Cancer Res 2010; 70: 2307-17.

68 Zoubeidi A, Zardan A, Beraldi E, Fazli L, Sowery R et al. Cooperative interaction between androgen receptor (AR) and heat-shock protein 27 facilitate AR transcriptional activity. Cancer Res 2007; 67: 10455-65.

69 Murai J, Huang SY, Das BB, Renaud A, Zhang Y et al. Trapping of PARP1 and PARP2 by clinical PARP inhibitors. Cancer Res 2012; 72: 5588-99.

70 Chi KN, Ellard SL, Hotte SJ, Czaykowski P, Moore M et al. A phase II study of sorafenib in patients with chemo-naive castration-resistant prostate cancer. Ann Oncol 2008, 19: 746-51.

71 Pinto A, Merino M, Zamora P, Redondo A, Castelo B et al. Targeting the endothelin axis in prostate carcinoma. Tumour Biol 2012; 33: 421-6.

72 Nelson JB, Fizazi K, Miller K, Higano C, Moul JW et al. Phase 3, randomized, placebocontrolled study of zibotentan (ZD4054) in patients with castration-resistant prostate cancer metastatic to bone. Cancer 2012; 118: 5709-18.

73 Isaacs JT, Antony L, Dalrymple S, Brennen WN, Gerber S et al. Tasquinimod is an allosteric modulator of HDAC4 survival signaling within the compromised cancer microenvironment. Cancer Res 2012; 73: 1386-99.

74 Pili R, Haggman M, Stadler WM, Gingrich JR, Assikis VJ et al. Phase II randomized, doubleblind, placebo-controlled study of tasquinimod in men with minimally symptomatic metastatic castrate-resistant prostate cancer. J Clin Oncol 2011; 29: 4022-8.

75 TRACON Pharmaceuticals Announces Dosing of Initial Three Cancer Patients in a Phase 1 Clinical Trial with TRC105, a Human Chimeric Antibody. http:// www.traconpharma.com/content/pr_01_9_08.html.

76 Kantoff PW, Higano CS, Shore ND, Berger ER, Small EJ et al. Sipuleucel-T immunotherapy for castration-resistant prostate cancer. N Engl J Med 2010; 363: 411-22.

77 Gulley JL, Madan RA, Schlom J. Impact of tumour volume on the potential efficacy of therapeutic vaccines. Curr Oncol 2011; 18: e150-7.

78 Madan RA, Arlen PM, Mohebtash M, Hodge JW, Gulley JL. Prostvac-VF: a vector-based vaccine targeting PSA in prostate cancer. Expert Opin Investig Drugs 2009; 18 1001-11.

79 Kantoff PW, Schuetz TJ, Blumenstein BA, Glode LM, Bilhartz DL et al. Overall survival analysis of a phase II randomized controlled trial of a Poxviral-based PSA-targeted immunotherapy in metastatic castration-resistant prostate cancer. J Clin Oncol2010 28: 1099-105.

80 Disis ML, Bernhard H, Shiota FM, Hand SL, Gralow JR et al. Granulocyte-macrophage colony-stimulating factor: an effective adjuvant for protein and peptide-based vaccines. Blood 1996; 88: 202-10.

81 http://www.clinicaltrials.gov.

82 Tarhini A, Lo E, Minor DR. Releasing the brake on the immune system: ipilimumab in melanoma and other tumors. Cancer Biother Radiopharm 2010; 25: 601-13.

83 Topalian SL, Hodi FS, Brahmer JR, Gettinger SN, Smith DC et al. Safety, activity, and immune correlates of anti-PD-1 antibody in cancer. N Eng/ J Med 2012; 366: 2443-54.

84 Smith MR, Saad F, Coleman R, Shore N, Fizazi K et al. Denosumab and bonemetastasis-free survival in men with castration-resistant prostate cancer: results of a phase 3, randomised, placebo-controlled trial. Lancet 2012; 379: 39-46.

85 Fizazi K, Carducci M, Smith M, Damiao R, Brown J et al. Denosumab versus zoledronic acid for treatment of bone metastases in men with castration-resistant prostate cancer: a randomised, double-blind study. Lancet 2011; 377: 813-22.

86 Sartor O, Reid RH, Hoskin PJ, Quick DP, Ell PJ et al. Samarium-153-Lexidronam complex for treatment of painful bone metastases in hormone-refractory prostate cancer. Urology 2004; 63: 940-5.

87 Han SH, de Klerk JM, Tan S, van het Schip AD, Derksen BH et al. The PLACORHEN study: a double-blind, placebo-controlled, randomized radionuclide study with ${ }^{186} \mathrm{Re}$ etidronate in hormone-resistant prostate cancer patients with painful bone metastases. Placebo Controlled Rhenium Study. J Nucl Med 2002; 43: 1150-6.

88 Lewington VJ, McEwan AJ, Ackery DM, Bayly RJ, Keeling DH et al. A prospective randomised double-blind crossover study to examine the efficacy of strontium-89 in pain palliation in patients with advanced prostate cancer metastatic to bone. Eur $J$ Cancer 1991; 27: 954-8.

89 Porter AT, McEwan AJ. Strontium-89 as an adjuvant to external beam radiation improves pain relief and delays disease progression in advanced prostate cancer: results of a randomized controlled trial. Sem Oncol 1993; 20: 38-43.

90 Nilsson S, Franzen L, Parker C, Tyrrell C, Blom R et al. Bone-targeted radium-223 in symptomatic, hormone-refractory prostate cancer: a randomised, multicentre, placebo-controlled phase II study. Lancet Oncol 2007; 8: 587-94.

91 Parker CC, Pascoe S, Chodacki A, O'Sullivan JM, Germa JR et al. A randomized double-blind, dose-finding, multicenter, phase 2 study of radium chloride ( $R$ a 223) in patients with bone metastases and castration-resistant prostate cancer. Eur Urol 2013; 63: 189-97.

92 Parker C, Heinrich D, O'Sullivan JM, Fosså S, Chodacki A et al. Overall survival benefit of radium-223 chloride (Alpharadin) in the treatment of patients with symptomatic bone metastases in castration-resistant prostate cancer (CRPC): a phase III randomized trial (ALSYMPCA). Eur J Cancer 2011; 47(Suppl 2): 3. 